\title{
Female Genital Mutilation: A Secondarv Research on its Effects and Impacts in the Lives of Young Girls and Women
}

\author{
Article by Mbangwana Mefor Bongbi Epse Malabo Ii \\ Public Health, Texila American University \\ E-mail: mbangwanamefor@yahoo.com
}

\begin{abstract}
Background: World Health Organisation (WHO) has been putting a lot of efforts to end female genital mutilation and together with global efforts that has intensified in recent there is a rising awareness of the numerous complications that go with the process, usually later in the life of the adult female. To examine the effect and impacts on these individuals is vital as prevalence occurs in many countries and the awareness of the health risk has to be ascertain because it is associated with physical, emotional and social health risks which is paramount to the cubing of this practice. This research aims to conduct a review of data so as to address the probability of stopping the act completely in all countries in the world

Methods: A mixed method synthesis was applied comparing the effects and impacts in different countries mostly in the African continent in ten different articles obtained from the Open Access Library Journal database, manually scanning of reference lists and summary feed from international organisations such as WHO, UNICEF and UN. The articles included quantitative and qualitative studies with statistical results and analysis. There were also studies carried out on the environmental issues as related to the act. The articles were in three different languages which included English, French and Spanish.

Results: The study population was made up of victims of the female genital mutilation and health professional who understood the process. The percentage of those who were unaware of the risk was $57.4 \%$ and the percentage of those who did not have formal education was $77.6 \%$. There was also a high percentage of prevalence which was represented by $52 \%$.

Conclusion: Female genital mutilation is an act which is supposed to be carried out with much precaution of the socio-cultural beliefs have to be maintained with a possibility of reclassifying the act.
\end{abstract}

Keywords: Female Genital Mutilation, prevalence, health risk.

\section{Background}

Female genital mutilation refers to all procedures involving partial or total removal of external female genitalia or other injury to the female genital organs for cultural or non-therapeutic reasons. According to the WHO classification of 1995 used in a study designed in November 2008 there are of four types, type I consist of clitoridectomy, type II is excision, type III is infibulations and type IV which are all the others forms performed for non-medical purposes. The practice of female genital mutilation is an act deeply rooted in tradition which violates human rights for the girl child and is found in about 30 countries in the world especially in Sub-Saharian Africa, having negative consequences for the health and quality of life in women. This practice is carried out in some Asian countries (Indonesia and Malaysia), Middle East countries (Yemen, Arab Emirates and Iraq) and in the western, eastern and north-eastern African countries but with many people who have immigrated we find some of them who practiced in Europe, North America and Australia, with a total of about 140 million girls and women circumcised in the world $[1,2,8,9,10]$.

It is a ritual with strong socio-cultural roots and superstition giving cultural identity, family honour and defines members of the society with the time of the operation being carried out varying across and within countries. This usually occurs before the end of childhood generally between ages 4 and 10 years $[1,2,4,8,9]$. This practice has an adverse impact on health with long term psychological, physiological, and sexual effects, usually which could be immediate or late, ranging from pains, 
bleeding, obstetrical complications, haemorrhage, psychological trauma, infections and transmission of diseases due to the method practiced in this act usually without anaesthesia $[2,6,8,10]$. The ten top countries that practice this include Chad, Burkina Faso, Gambia, Sudan, Djibouti, Somalia, Ethiopia, Mali, Egypt and Guinea and the prevalence varies amongst countries with the highest in Somalia. The world's first campaign against this act was in Egypt, and in July 2003 at the African Union second summit, the Maputo Protocol was adopted promoting women's rights and calling for an end of Female Genital Mutilation. This finally came in to force by 2005 with 25 -member countries ratifying it. The purpose of this study is to examine the different effects and complications resulting from female genital mutilation and to evaluate the current status following campaigns against this act which goes against the liberty of the girls and women.

\section{Methods}

The study involved a total of nine articles which were selected between the year $2009-2015$ in which female genital mutilation was talked about both from the victim point of view and from that of the medical practitioner. Most of the research in the articles was carried out in African countries where the act is frequently practiced and deeply rooted in tradition. Most of the studies ranged from three months and a few of them for more than a year. This study is thus designed to know more about the effects of female genital mutilation in the later life of the girl child and also to know the level of awareness of the health risk incurred by this process.

They used the random sampling method for the population size in which they considered as participants girls who have undergone female genital reproduction and of reproductive ages as from 14years to 49 years while for the professionals the participants here were those who have come across victims and those who have practiced this process before. In most cases we see that the morbidity and mortality indices are difficult to obtain since during consultation of most patients it is the data of the disease occurrence that is taken into consideration. The professionals involved here are usually trained personnel which permits them to identify the particular type of female genital mutilation practiced.

The data analysed was obtained from secondary data and the collection method applied for the girls and women were interviews were visits were made to their homes and written permission was obtained for the data to be collected, the interview was verbal and the answers of the participants were transcribed. For the health professionals a comprehensive questionnaire covering health issues related to female genital mutilation was given.

The measures involved here constituted the dependent variables as to the effects of the practice in their lives and clinical variables which involves the different occurrence of health hazards encountered and classified in to immediate and long term complications in the patients. The immediate complications include excessive bleeding from the genitalia where the act was practiced causing acute anaemia (haemoglobin level below $11 \mathrm{~g} / \mathrm{l}$ ), infections such as tetanus, lower urinary tract infections, septicaemia, vulvovaginitis, fibrosis, cheloids, while the long-term complications are usually obstetrical, synechia, organic dispareunia, and many others. We see that the prevalence cannot be minimised as it can cause long term effects right up to child birth.

The differences in values of the dependent variable which are the effects of this act on the girls and women were assessed by chi-square and the $\mathrm{P}<0.05$ was considered significant.

\section{Results and discussion}

It is seen that the type of mutilation varies within and between countries with $90 \%$ of cases being type I, II and IV while $10 \%$ is the type III procedure. In data obtained from WHO, prevalence of female genital mutilation in Sudan was $89 \%$, in Somalia was $100 \%$ and the difference in prevalence may be explained by cultural factors, believes, habits and environmental factors. The most frequently encountered problem was sexual difficulties with anorgasmia.

Taking the case of the different level of awareness of the physical health risk in female that was carried out in Nigeria, of 380 respondents, it was seen that $162(42.6 \%)$ respondents were aware while $218(57.4 \%)$ were unaware of the risk involved in the practice of female genital mutilation. 163 (42.9\%) respondents were aware of the emotional health risk while $217(27.1 \%)$ were unaware and with regards to social health effects, 105 (27.6\%) of the respondents were aware while $275(74.4 \%)$ 
were unaware (Table 1). Among those who had non-formal education it was noted that $24(22.4 \%)$ are aware of health risks while $83(77.6 \%)$ are unaware of the risk involved in female genital mutilation (Table 2).

While in another research the data collected on a total of 871 health cases in Gambia, it showed that the health complications depend on the type of female genital mutilation carried out. Type I accounted for $66.2 \%$ (577) of the cases registered, type II for $26.3 \%$ (229) and type III for $7.5 \%$ (65) and the complications whether immediate or late was $23.7 \%$ (137) in type I, 55.0\% (126) in patients with type II and 55.4\% (36) with type III. $12.6 \%$ that is 110 patients sought for consultation for immediate complication while $21.7 \%$ (189) of them for late complications while $34.3 \%$ (299) sought for gynaecological consultations (Table 3).

From table 1 there is the level of awareness of prevalence of female genital mutilation with approximately $60 \%$ of participants unaware of the dangers in the carrying out of this procedure meaning they have no idea of the health risk they are running. Table 2 gives us an idea of the knowledge depending on the level of education and it is seen that those who are less educated just accept the procedure not knowing the dangers, eventually complications that occur later are not linked in their mind to the act. Table 3 talks about the different possible disorders that come along with the act of the mutilation from the immediate effects to long term disorders, and it is seen that the highest prevalence are infections as the hygiene of these girls are not taken in to consideration with the difficult environmental conditions in most of the areas.

Table 1. The awareness of health risks involved in female genital mutilation in women

\begin{tabular}{|l|l|l|l|}
\hline Health risks & Aware & Unaware & Total \\
\hline Physical & $162(42.6)$ & $218(57.4)$ & 380 \\
\hline Emotional & $163(42.9)$ & $217(57.1)$ & 380 \\
\hline Social & $105(27.6)$ & $275(72.4)$ & 380 \\
\hline Total & $143(37.7)$ & $237(62.3)$ & 380 \\
\hline
\end{tabular}

Table 2. The awareness of health risk according to education level

\begin{tabular}{|l|l|l|l|}
\hline Level of education & Aware & Unaware & Total \\
\hline Non formal & $24(22.4 \%)$ & $83(77.6 \%)$ & $107(28.2 \%)$ \\
\hline Primary & $32(29.6 \%)$ & $76(70.4 \%)$ & $108(28.4 \%)$ \\
\hline Secondary & $42(46.7 \%)$ & $48(53.3 \%)$ & $90(23.7 \%)$ \\
\hline Tertiary & $45(60 \%)$ & $30(40 \%)$ & $75(19.7 \%)$ \\
\hline Total & $143(37.6 \%)$ & $237(62.4 \%)$ & $380(100 \%)$ \\
\hline
\end{tabular}

Table 3. Prevalence in female genital mutilation in the different types and some complications

\begin{tabular}{|l|l|l|l|l|}
\hline & \multicolumn{5}{|l|}{ Female genital mutilation type } \\
\hline & Tpye I & Type II & Type III & Total \\
\hline Cases & $577(66.2 \%)$ & $229(26.3 \%)$ & $65(7.5 \%)$ & $871(100 \%)$ \\
\hline $\begin{array}{l}\text { Complications } \\
\text { directly from FGM }\end{array}$ & $137(23.7 \%)$ & $126(55.0 \%)$ & $36(55.4 \%)$ & $299(34.3 \%)$ \\
\hline $\begin{array}{l}\text { Immediate } \\
\text { complications }\end{array}$ & $36(26.3 \%)$ & $55(43.7 \%)$ & $19(52.8 \%)$ & $110(36.8 \%)$ \\
\hline Infections & $32(88.9 \%)$ & $48(87.3 \%)$ & $16(84.2 \%)$ & $96(87.3 \%)$ \\
\hline Haemorrhage & $10(27.8 \%)$ & $23(41.8 \%)$ & $7(36.8 \%)$ & $40(36.4 \%)$ \\
\hline Anaemia & $15(41.7 \%)$ & $17(30.9 \%)$ & $11(52.6 \%)$ & $42(38.2 \%)$ \\
\hline Late complications & $101(73.7 \%)$ & $71(56.3 \%)$ & $17(47.2 \%)$ & $189(63.2 \%)$ \\
\hline Abnormal scarring & $87(86.1 \%)$ & $63(88.7 \%)$ & $11(64.7 \%)$ & $161(85.2 \%)$ \\
\hline
\end{tabular}

\section{Conclusion}

All forms of female genital mutilation lead to a high percentage of complications both immediate and long term especially infections, haemorrhage and anaemia with the frequency of complications 
varying depending on the degree of mutilation. With such adverse effects that occur the continuation of this process is supposed to be abolished or the procedure reviewed since it has a strong social and cultural root. The measures taken to eliminate this procedure have not really influenced the incidence of the act. For the reviewing of the process, harm reduction and behaviour change are applied as education on the associated risk is to be made known to those who practice the act. The process can be softened to reduce the prevalence level and probably reclassifying the act, this will permit the respect of the cultural differences and at the same time watching over the health of women. There is also the need of structural improvement which includes public education and changes to specific cultural beliefs. Viewing the control from the point of decision makers and leaders in the community including religious leaders, they need to use as channels radio stations, workshops, television stations as methods of intervention to modify the cultural beliefs.

\section{Acknowledgements}

My sincere gratitude goes out to all those who have assisted me in one way or the other in the fulfillment of my "Capstone Project".

First of all, I would like to thank the academic staff of The Texila American University for giving me the chance to acquire more knowledge and for their support.

My sincere gratitude goes to my colleagues of The Texila American University Online who assisted me without relenting efforts whatever the time I try to get to them.

Special thanks go to my friends and husband who even without having an idea of the course I am going through helped me out with a lot of research work.

Above all to God Almighty without whom I wouldn't have gone through this work.

\section{Reference}

[1]. Ali, Abdel Aziem A. (2012). Knowledge and attitudes of female genital mutilation among midwives in Eastern Sudan Reproductive Health 23 Vol 9 Issue 1 ISSN 1742-4755 doi.org/10.1186/1742-4755-9-23

[2]. A O. Okhiai, A O.B. Idonije, E.C. Asika, (2011) Awareness of Health Risks of Female Genital Mutilation Among Women of Child Bearing Age in Two Rural Communities in Nigeria Asian Journal of Medical Sciences 3(6): 223-227 ISSN:2040-8773

[3]. Adriana Kaplan-Marcusan, Pere Torán-Monserrat, Juana Moreno-Navarro, Ma Jose Castany Fàbregas, Laura Muñoz-Ortiz (2009). Perception of primary health professionals about Female Genital Mutilation: from healthcare to intercultural competence BMC Health Services Research SP 11, Vol 9 Issue 1 ISSN-1472-6963 https://doi.org/10.1186/1472-6963-9

[4]. Christiane, Rochon. (2007). La circoncision des femmes en Afrique : repenser les politiques de santé. Les ateliers de l'éthique. 2.

[5]. Dalal, K., Lawoko, S., \& Jansson, B. (2010). Women's attitudes towards discontinuation of female genital mutilation in Egypt. Journal of Injury and Violence Research, 2(1), 41-47. http://doi.org/10.5249/jivr.v2i1.33

[6]. Essa M. Arafa, Amany M. Abdelghany, Nadia M. Madkour, Wael S. Nossair, Ekramy A. Mohamed (2014). Survey Study of Acute and Long-Term Effects of Female Genital Mutilation among Women in Sharkia Governorate Open Journal of Obstetrics and Gynaecology, 4, 874-880 http://dx.doi.org/10.4236/ojog.2014.414123

[7]. Fikrie, Zenebe. (2010). Factors Associated with Perceived Continuation of Females' Genital Mutilation among Women in Ethiopia. Ethiopian journal of health sciences. 20. 49-53. 10.4314/ejhs.v20i1.69425.R.A. Ragab, Ahmed. (2008). Some Ethical Considerations Regarding Medicalization of Female Genital Mutilation/cutting (Female Circumcision). Revista Latinoamericana de Bioética, ISSN 1657-4702, Vol. 8, No. $14,2008.8$.

[8]. Jones S.D., Ehiri J., Anyanwu E. (2004) Female genital mutilation in developing countries: An agenda for public health response European Journal of Obstetrics Gynecology and Reproductive Biology, 116 (2) , pp. 144151.

[9]. Kaplan, A., Hechavarría, S., Martín, M., \& Bonhoure, I. (2011). Health consequences of female genital mutilation/cutting in the Gambia, evidence into action. Reproductive Health, 8, 26. http://doi.org/10.1186/17424755-8-26 
[10]. Kizilhan, Jan. (2011). Impact of psychological disorders after female genital mutilation among Kurdish girls in Northern Iraq. The European Journal of Psychiatry. 25. 92-100. 10.4321/S0213-61632011000200004.

[11]. Lhagadang Foumsou, Richard Norbert Nglalé, Jeanne Fouedjio, Gédéon Ndakmissou, Bray Madoué Gabkika, Sadjoli Damthéou, Philip Njotang Nana, Abdoulaye Sépou (2015). Obstetric Complications Due to Female Genital Mutilation (FGM) at N'Djamena Mother and Child Hospital (Chad), Open Journal of Obstetrics and Gynecology, 5, 784-788. http://dx.doi.org/10.4236/ojog.2015.514110

[12]. World Health Organisation: Eliminating Female Genital Mutilation. Geneva, 2008:1-47 